\title{
Neural network computation for the evaluation of process rendering: application to thermally sprayed coatings
}

\author{
Sofiane Guessasma ${ }^{1}$ and David Bassir ${ }^{2,3, *}$ \\ 1 INRA, UR1268 Biopolymères Interactions Assemblages, 44300 Nantes, France \\ 2 CMLA, ENS-Cachan, 61 av. du Président Wilson, 94235 Cachan Cedex, France \\ 3 UTBM, 90010 Belfort Cedex, France
}

Received 18 May 2017 / Accepted 6 June 2017

\begin{abstract}
In this work, neural network computation is attempted to relate alumina and titania phase changes of a coating microstructure with respect to energetic parameters of atmospheric plasma straying (APS) process. Experimental results were analysed using standard fitting routines and neural computation to quantify the effect of arc current, hydrogen ratio and total plasma flow rate. For a large parameter domain, phase changes were $10 \%$ for alumina and $8 \%$ for titania with a significant control of titania phase.
\end{abstract}

Key words: Artificial neural network, Statistical analysis, Process engineering.

\section{Introduction}

Thermal spraying process is a technological process for coating manufacturing implementing a wide variety of materials and processes [1, 2]. The coating quality control of such technique generally considers the monitoring of the molten feedstock particle characteristics (i.e., velocity and temperature) before their impingement onto the work piece to be covered [3]. These characteristics are intimately related to the particle semi-molten state and proved to be sensitive to processing parameters [4-7]. These influence significantly the coating in-service properties [8] and microstructure features [9]. Among these features, change of phases which can be related to powder particle evaporation and thus to deposition efficiency. This paper deals with predictability of alumina and titania content changes in the microstructure when atmospheric plasma straying (APS) energetic parameters are varied.

\section{Experimental investigation}

Experiments were realized using a Sulzer Metco F4 gun operating at power levels up to $50 \mathrm{~kW}$. Atmospheric plasma spraying was carried out using a gas mixture of hydrogen and argon as a plasma gas. The argon gas was also considered as a carrier gas for the feedstock material injection. Its flow rate was fixed to 3.2 SLPM (standard litre per minute).

$\mathrm{Al}_{2} \mathrm{O}_{3}-\left(13\right.$ wt.\%) $\mathrm{TiO}_{2}$ (Metco 130) powder was used as a feedstock material whose range size is $-15+53 \mu \mathrm{m}$. Coatings realized with such feedstock material are related to industrial applications where good resistance to abrasive wear, sliding wear, friction and oxidation is required. Powder injection was external to the torch and directed perpendicular to the plasma flow and parallel to the torch trajectory. The powder feed rate was fixed at $22 \mathrm{~g} \mathrm{~min}^{-1}$. The distance separating the injector tip from the geometric axis of the gun (i.e., the injection distance) was fixed at $6 \mathrm{~mm}$.

Experiments considered three parameters: arc current $(I)$, argon primary plasma gas flow rate $\left(V_{\mathrm{Ar}}\right)$ and hydrogen secondary plasma gas flow rate $\left(V_{\mathrm{H}_{2}}\right)$. These parameters are known to significantly influence the plasma jet properties (enthalpy, temperature, velocity, etc.) and are mostly related to particle evaporation. Each of these parameters was varied individually to three values (low, medium and high levels). The other parameters were kept, at each time, to a reference condition. Coatings were realized on button substrates $(\phi 25 \mathrm{~mm} \times 10 \mathrm{~mm})$. After metallographic preparation, coating characterization was performed on cross sections revealing the microstructure shown in Figure 1. Microstructure features were essentially, alumina (dark grey phase), titania (clear grey phase), porosity and unmolten particles.

\section{Calculation principle}

Phase contents are calculated using image analysis assuming the following relationship

$$
P(\%)+I(\%)+A(\%)+T(\%)=100 \%
$$


(a)

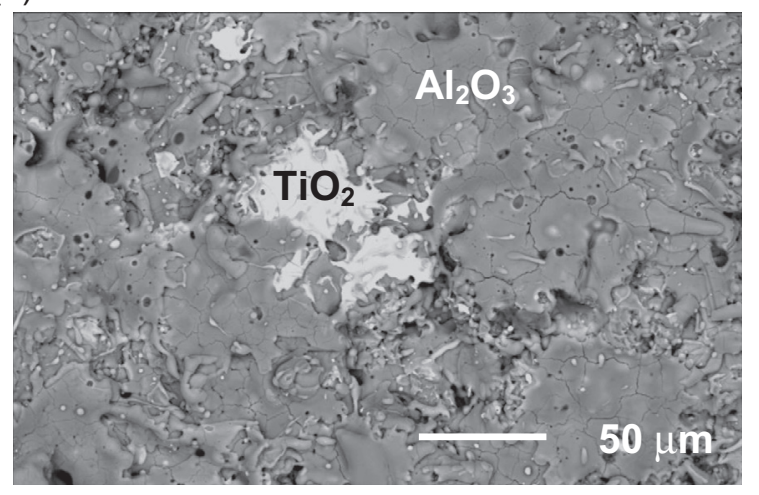

(b)

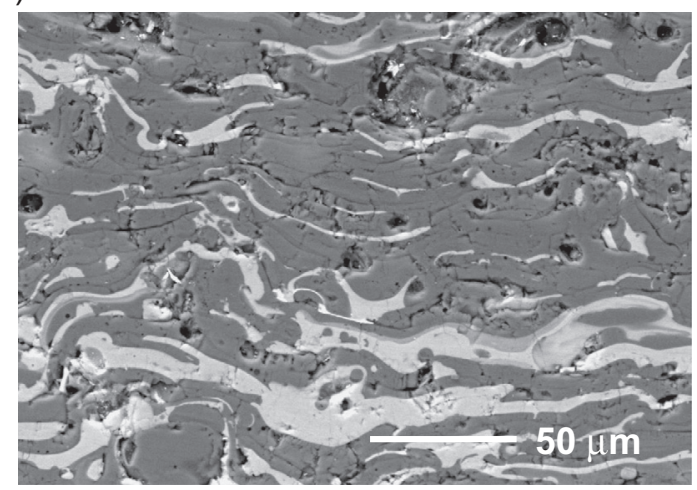

Figure 1. SEM micrographs of alumina - titania coating (a) top view, (b) cross section view.

where $P$ is the porosity content, $I$ is the unmolten particle percentage, $A$ is the ratio of alumina phase and $T$ is the ratio of titania phase.

In this calculation, $\operatorname{Ti}_{x} \mathrm{O}_{y}$ content is referred to titania phase. Calculations are performed on 10 random sections for each experimental condition.

For data processing, an artificial neural network (ANN) was used to relate energetic parameters (three inputs) to microstructure features including porosity, unmolten particle, alumina and titania contents (four outputs). A structure was optimized after 1000 cycles and revealed two hidden layers containing 10 neurons in the first one and five neurons in the second one. For a detailed description about neural computation, see for example [10-15].

A fitting routine was also used, and this concerned only $A(\%)$ and $T(\%)$ results. This routine is based on two criteria, namely the correlation factor $\left(R^{2}\right)$ and the adjusted coefficient of multiple determination $\left(R a^{2}\right)$ [16]. $R^{2}$ parameter provides the percentage of the data points that would be explained by the regression model. Thus, $R^{2}=1$ means that all points are described by the selected fitting function. It can be written as follows

$$
R^{2}=\frac{\sum_{i=1}^{n}\left(\hat{y}_{i}-y\right)^{2}}{\sum_{i=1}^{n}\left(y_{i}-y\right)^{2}}
$$

where $y_{i}, \hat{y}_{i}$ are, respectively, the dependent variable and the predicted (i.e., fitted) value. $n$ is the number of the observations. $y$ is mean value of the dependant variables.

$R a^{2}$ parameter determines the balance between the parameter number used in a regression model and the increasing of $R^{2}$. For example, five data points can be easily explained by a polynomial curve of sixth order as the derivative gives five solutions, i.e., all the data points passes through the curve with $R^{2}=1$ but this usually do not represent the true fitting curve. The definition of $R a^{2}$ parameter is as follows

$$
R a^{2}=\frac{(n-1) R^{2}-k}{n-1-k}
$$

where $k$ is the number of regression parameters.

\section{Results and discussion}

When considering different levels of energetic parameters, the phase content variation in the microstructure is attributed to particle evaporation (Figure 2). For a low plasma net energy corresponding, for example, to $0 \%$ hydrogen ratio, particle temperature distribution at the spray distance is assimilated to a Gaussian distribution (Figure 2a). When the net energy available is increased (hydrogen ratio at $35 \%$, for example), an abrupt limit appears at the temperature $3000{ }^{\circ} \mathrm{C}$, which states a limit for particle over which evaporation takes place (Figure 2b).

\subsection{Effect of arc current}

The effect of the arc current was studied considering three significantly different levels $350 \mathrm{~A}, 530 \mathrm{~A}$ and $750 \mathrm{~A}$ (Figure 3). The other processing parameters were kept to the reference condition. Experimental results show that alumina content increased linearly with the increase of arc current from $70 \%$ to $90 \%$ whereas titania content decreased from $10 \%$ to $5 \%$. Fitting routine allowed the following relationships

$$
\begin{aligned}
& A(\%)=57.4+0.04 I(\mathrm{~A}) ; \quad R^{2}=1.000 \\
& T(\%)=13.68-0.01 I(\mathrm{~A}) ; \quad R^{2}=0.977
\end{aligned}
$$

Artificial neural network (ANN) predicted results show a small non-linear behaviour similar to fitting curves. The scatter between experimental and predicted results is in the average less than $2 \%$ and $13 \%$ for alumina and titania, respectively. Arc current controlled better titania content as its value decreased by a factor of two compared to alumina increase between $350 \mathrm{~A}$ and $750 \mathrm{~A}$.

The decrease of titania content relative to the increase of arc current is explained by titania evaporation [17]. In fact, thermal stability of titania is larger than that of alumina because titania evaporation temperature is more important than that of alumina and stability of liquid state is shifted towards high temperatures in the case of titania [17]. However, titania has a low melting temperature, a low latent heat of fusion 
(a)

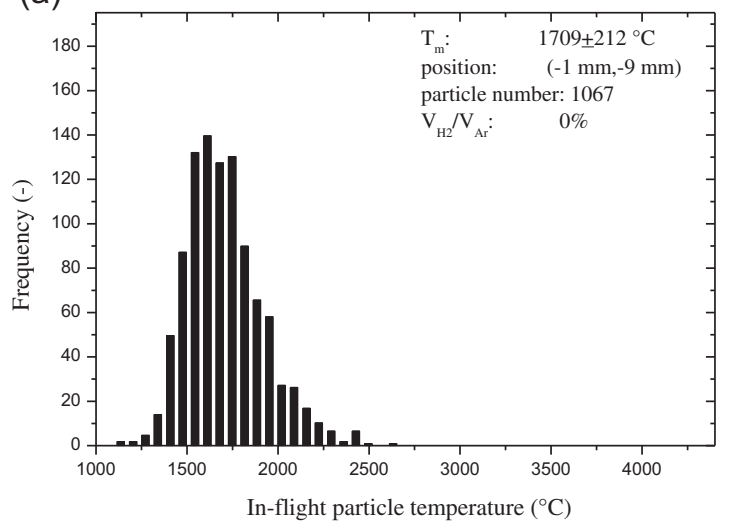

(b)

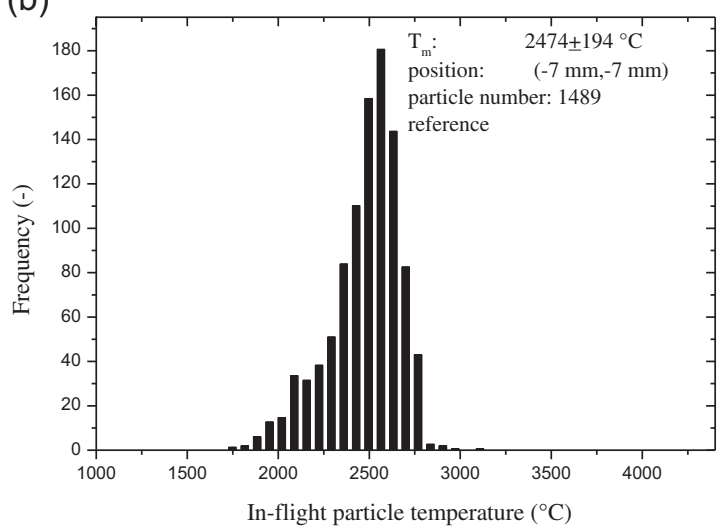

Figure 2. Evidence of particle evaporation when varying the net available energy in the plasma jet. (a) Case where plasma energy is low (hydrogen ratio fixed at $0 \%$ ). (b) Case where plasma energy is high (hydrogen ratio fixed at $35 \%$ ). Tm means average particle temperature. Position represents measurement location in the radial section of the plasma jet.

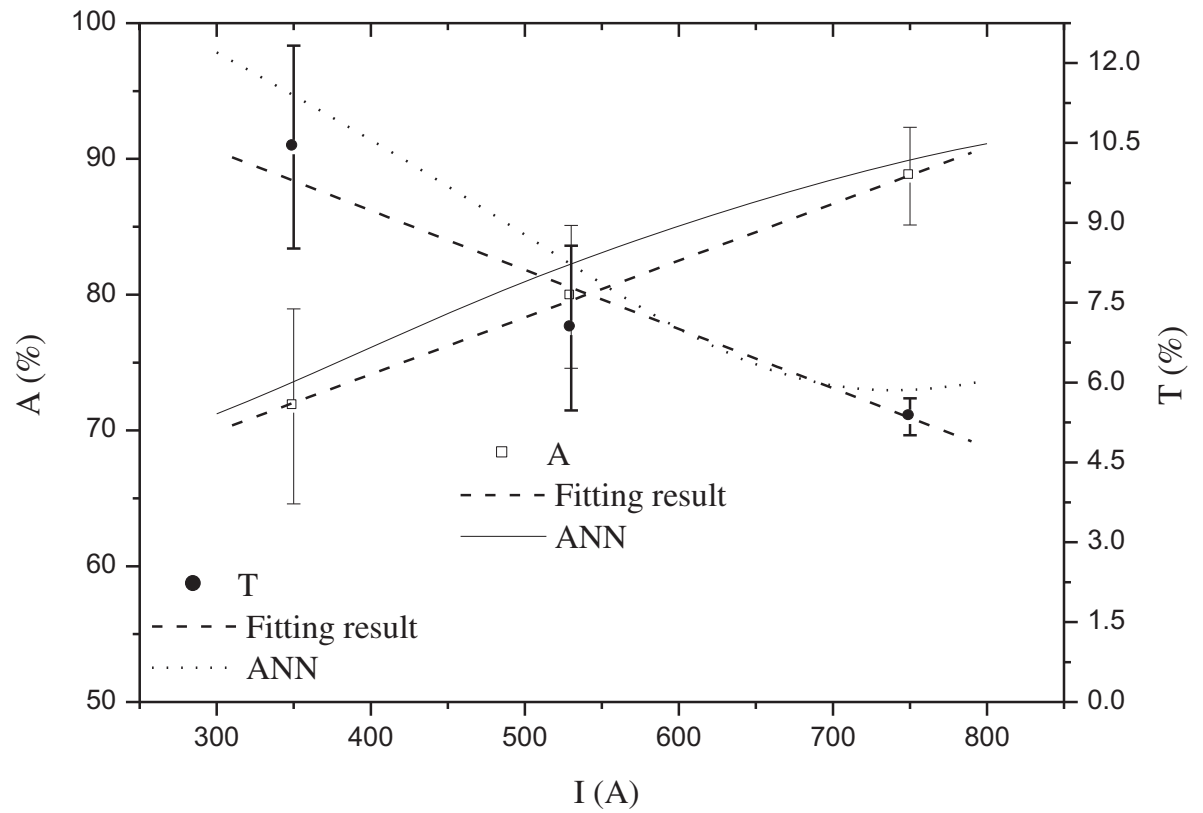

Figure 3. Effect of arc current on phase contents.

and a low specific heat molten state compared to alumina, which means that titania particle temperature drops rapidly in the plasma jet, which also causes high fraction of particle evaporation before substrate impingement [17]. In the counterpart and for low arc current, where alumina particles are still in the solid state, particles strike the substrate and rebound. This explains the low content of alumina in the microstructure. For higher electric powers, alumina content increases because of particle temperature improvement. Gell et al. [18] found a significant increase of alumina content in the microstructure when electric energy level is increased in the case of alumina-titania nano-structured powder. However, their results concerning Metco-130 powder show a stabilization of the phase content between 95 and $100 \%$ for the same increase of electric energy. This difference can be attributed to the fact that these authors used only argon gas for the plasma jet generation whereas in this study hydrogen was added to improve plasma jet enthalpy.

\subsection{Effect of total plasma gas flow rate}

The total plasma gas flow rate $\left(V_{\mathrm{Ar}}+V_{\mathrm{H}_{2}}\right)$ was varied from 40 to 70 SLPM (standard litre per minute) for a hydrogen ratio $\left(V_{\mathrm{H}_{2}} / V_{\mathrm{Ar}}\right)$ of $35 \%$ whereas the other parameters were kept to the reference condition (Figure 4). Experimental results show significant increase of titania content and a smaller 


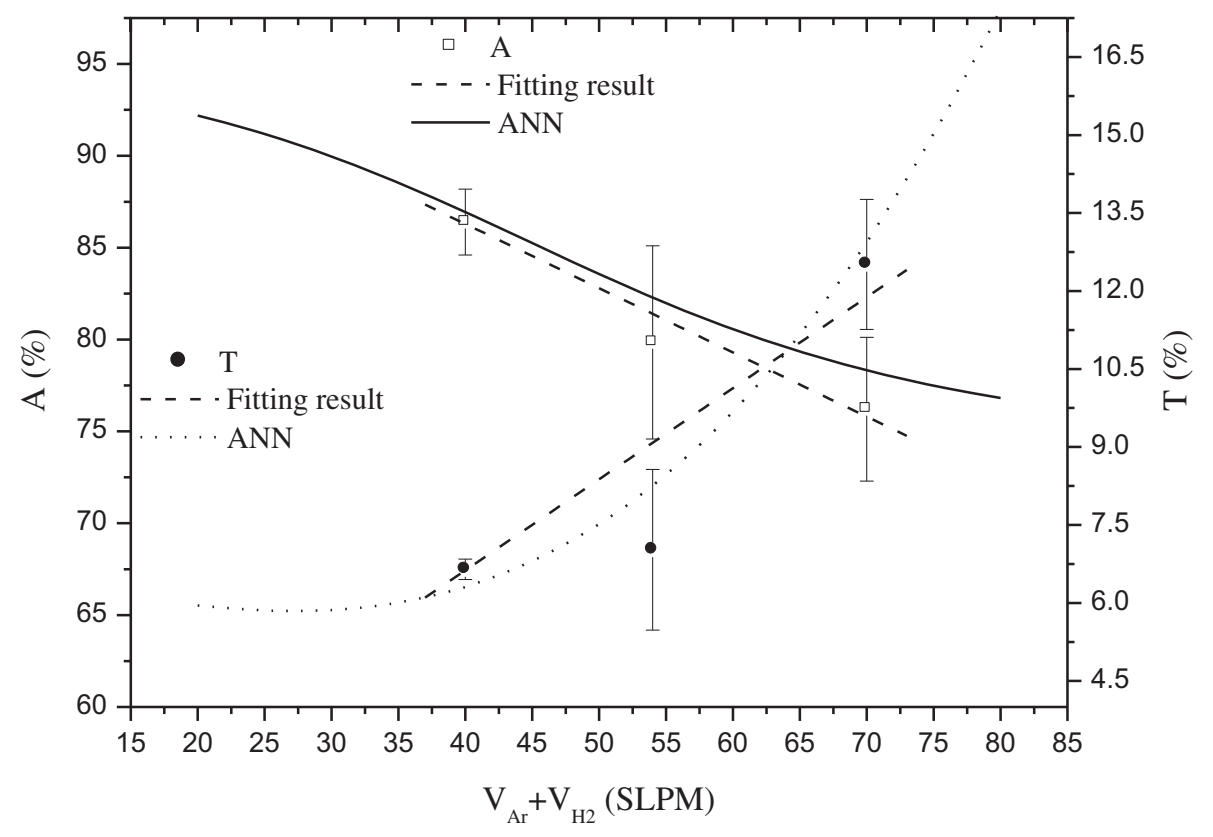

Figure 4. Effect of total plasma gas flow rate on phase contents.

decrease of alumina content. The rate of the linear relationships suggested by fitting routine show such trend

$$
\begin{gathered}
A(\%)=100-0.35\left(V_{\mathrm{Ar}}+V_{\mathrm{H}_{2}}\right)(\mathrm{SLPM}) ; \\
R^{2}=0.992 \\
T(\%)=0.18\left(V_{\mathrm{Ar}}+V_{\mathrm{H}_{2}}\right)(\mathrm{SLPM}) ; \quad R^{2}=0.952
\end{gathered}
$$

Predicted results show a stability of titania content at $6 \%$ for flow rates lower than 40 SLPM followed by a linear increase comparable to fitting result. Alumina content is predicted to decrease linearly with plasma gas flow rate similarly to fitting result.

Scatter of predicted results with respect to experimental ones is in the average around $2 \%$ and $9 \%$ for alumina and titania phases, respectively. The effect of total plasma gas flow rate is larger in the case of titania as its value was twice increased between 40 and 70 SLPM, from $6.5 \%$ to $12.5 \%$.

Alumina content was less sensitive to total plasma gas flow rate than titania compared to arc current. A decrease of less than $10 \%$ was obtained between 40 and 70 SLPM. Such effect is interpreted by the fact that plasma gas flow rate increases significantly particle velocity and shortens their interaction time in the plasma jet $[8,9]$. Moreover, plasma jet becomes more diffuse and thus causes the shrinkage of the core region where temperature exchanges are the most significant [2]. These aspects lower particle temperature and thus decrease alumina content in the microstructure. However, titania increase is interpreted by a low temperature range efficient for increasing titania content in the microstructure.

\subsection{Effect of hydrogen ratio}

Hydrogen ratio in the plasma gas was varied from $23 \%$ to $50 \%$ keeping the other parameters to the reference condition.
Figure 5 shows a slight increase of alumina content whereas titania content increase is more significant. Linear relationships were found to best describe such tendency

$$
\begin{array}{ll}
A(\%)=67+0.37\left(V_{\mathrm{H}_{2}} / V_{\mathrm{Ar}}\right)(\%) ; & R^{2}=0.997 \\
T(\%)=16-0.22\left(V_{\mathrm{H}_{2}} / V_{\mathrm{Ar}}\right)(\%) ; & R^{2}=0.776
\end{array}
$$

In the case of titania phase, the ANN predicted result shows that titania content decrease is more effective between $20 \%$ and $37 \%$ of hydrogen fraction. For higher fractions, titnia content was predicted around $8 \%$. In the case of alumina content, predicted and fitting results are in good agreement. The scatter between predicted and experimental results is in the average $3 \%$ and $14 \%$ for alumina and titania phases, respectively.

As in the case of arc current, the predicted result shows a significant effect on titania phase, which decreases by a factor of two between $23 \%$ and $50 \%$ whereas alumina increase is $15 \%$ in the same range. Hydrogen effect is related to the improvement of plasma jet enthalpy, thermal conductivity and viscosity, as demonstrated previously [9, 19-21]. All these factors increase the available energy for particle heating and explain the increase of alumina content and the decrease of titania content in the microstructure.

\subsection{Combined effects between process parameters}

In order to better capture the effect of process parameters using the statistical analysis, instead of varying individually each parameter, parameter combinations are considered as illustrated in Figure 6a. This allows to drag a cubic grid in the parameter space with a resolution of at least 6 points for each parameter. The total number of combinations is thus 216 . Figure $6 \mathrm{~b}$ shows histograms representing the frequency of parameter 


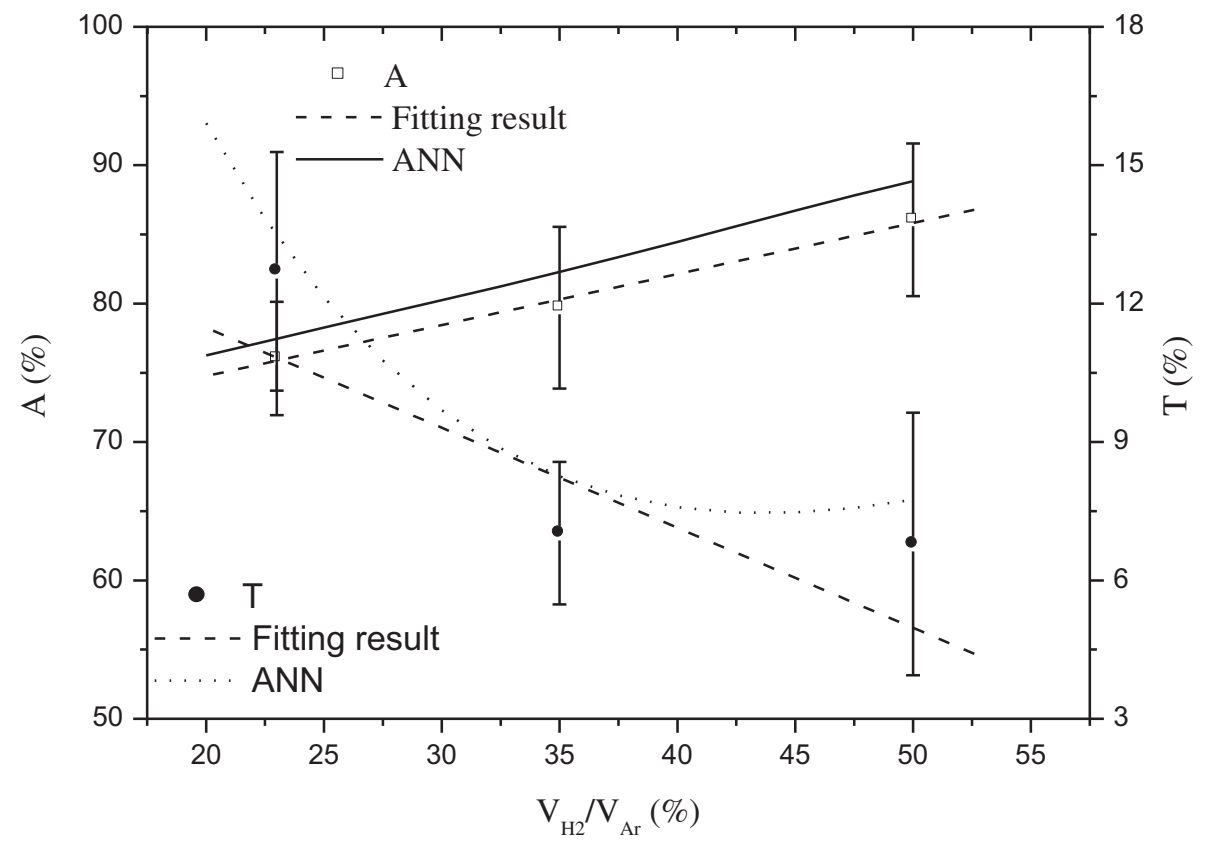

Figure 5. Effect of hydrogen ratio on phase contents.

(a)

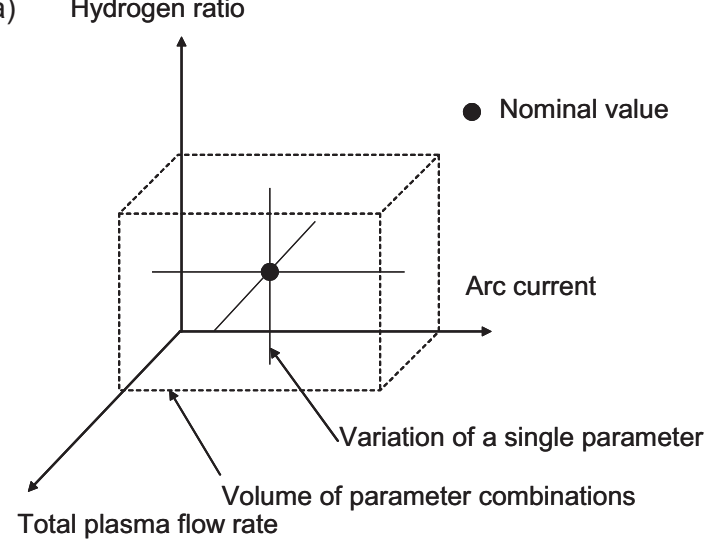

(b)

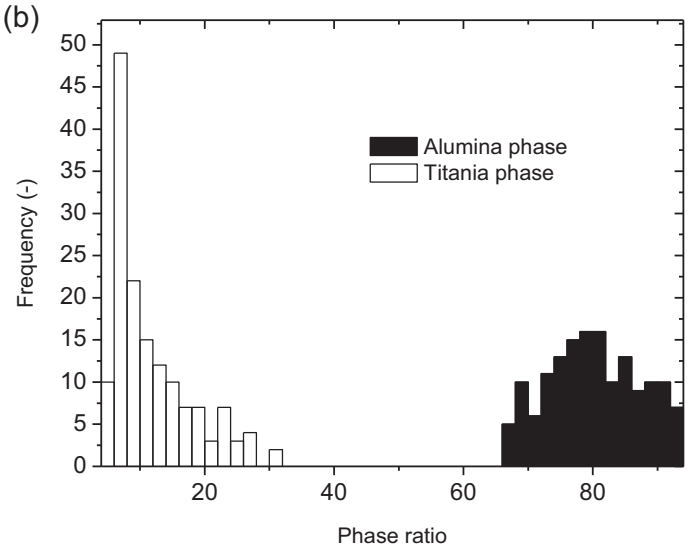

Figure 6. (a) Illustration of parameter combinations in the prediction space. (b) Predicted phase ratios as function of the combinations identified in the parameter space.

combinations for a given value of alumina and titania phases. Alumina ratio is predicted to vary between $67 \%$ and $93 \%$ and titania ratio between $5 \%$ and $31 \%$ whatever is the parameter combination. As in the case of the individual effects, titania phase variation is more sensitive to parameter variations compared to alumina phase. Only few combinations are predicted to cause the increase the titania ratio in the microstructure.

The analysis of the results of the parameter combinations show capabilities of predicting the average variation of the phase ratio with respect to each process parameter whatever is the values of the other parameters. To do so, the predicted ratios are averaged for a fixed value of the process parameters. This analysis confirms and generalizes the parameter effects identified by varying each parameter individually and fixing the other parameters to a prescribed value. Figure 7 shows the evolution of the phase ratios as function of the studied parameters. In the case of the arc current (Figure 7a), an increase of the alumina phase content and decrease of the titania phase content are predicted when this parameter is increased. This effect is thus in good agreement with the one revealed in Figure 3. The error bars represents in Figure 7a the scatter of the ratio values. These values are issued from varying the hydrogen ratio and the total plasma flow rate. It is worth mentioning that these error bars are larger in the case of titania phase showing again that the scatter in the titania predicted values is significant. 
(a)

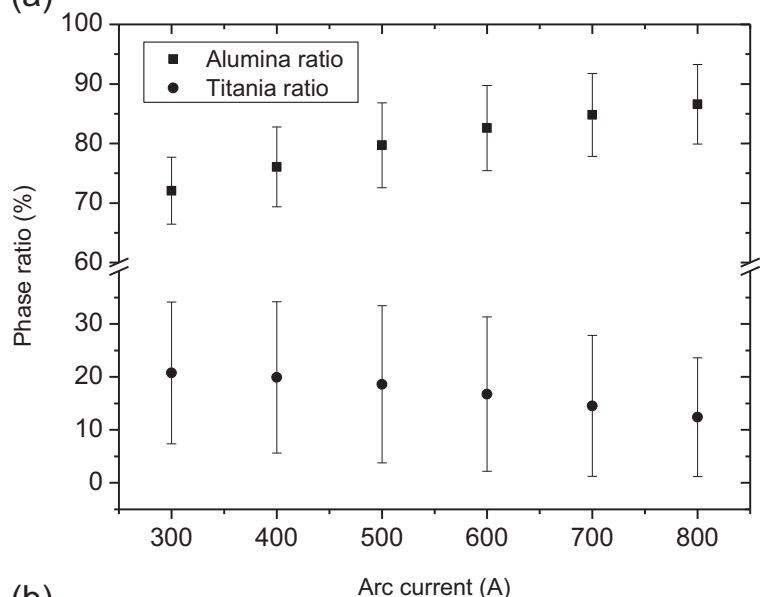

(b)

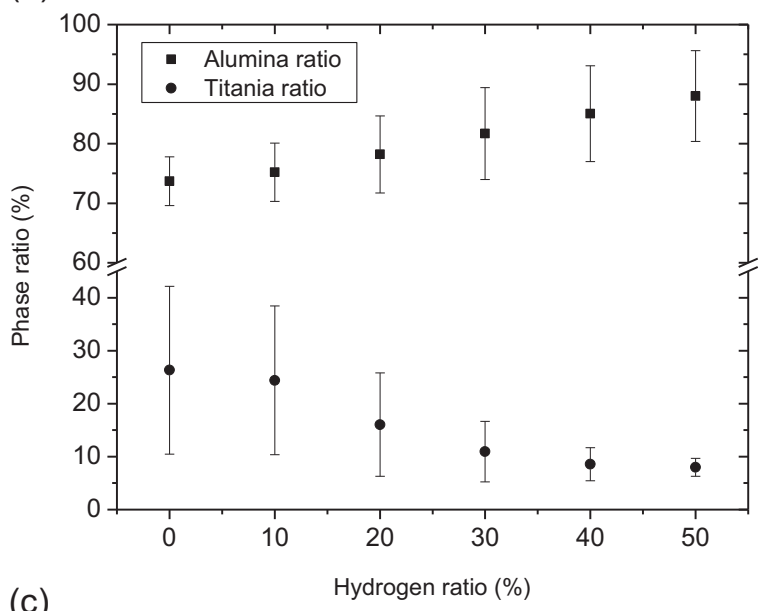

(c)

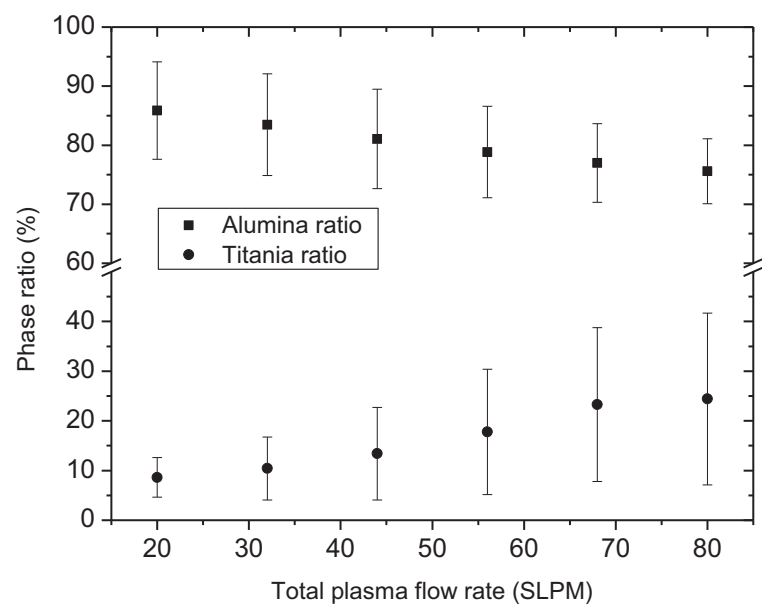

Figure 7. Analysis of the parameter combinations by varying one parameter and selecting the possible combinations with the other studied parameters. Case of the (a) arc current, (b) hydrogen ratio and (c) total plasma flow rate.

Figure $7 \mathrm{~b}$ shows the tendency of phase variation as function of the hydrogen ratio. As in the case of Figure 5, the titania ratio is found to decrease whereas the alumia phase is found to increase when increasing the hydrogen ratio. The analysis of (a)

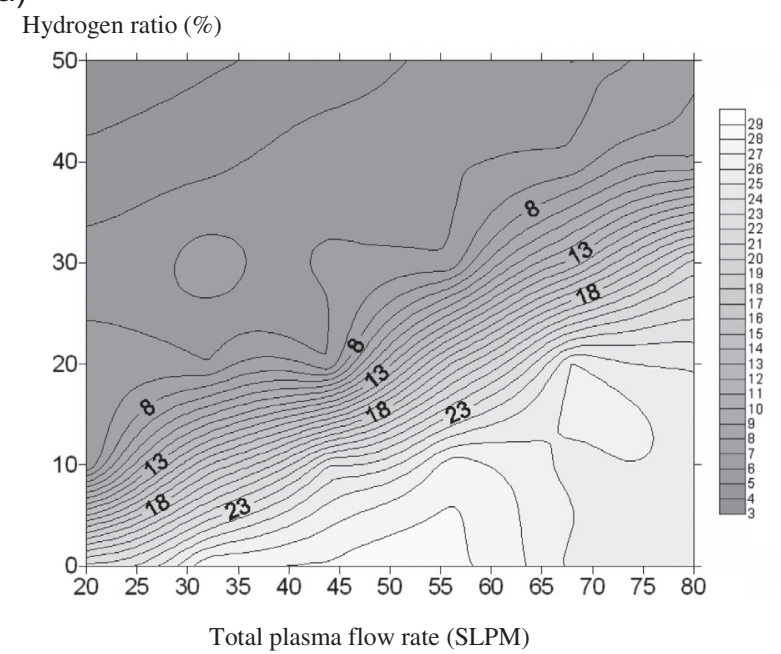

(b)

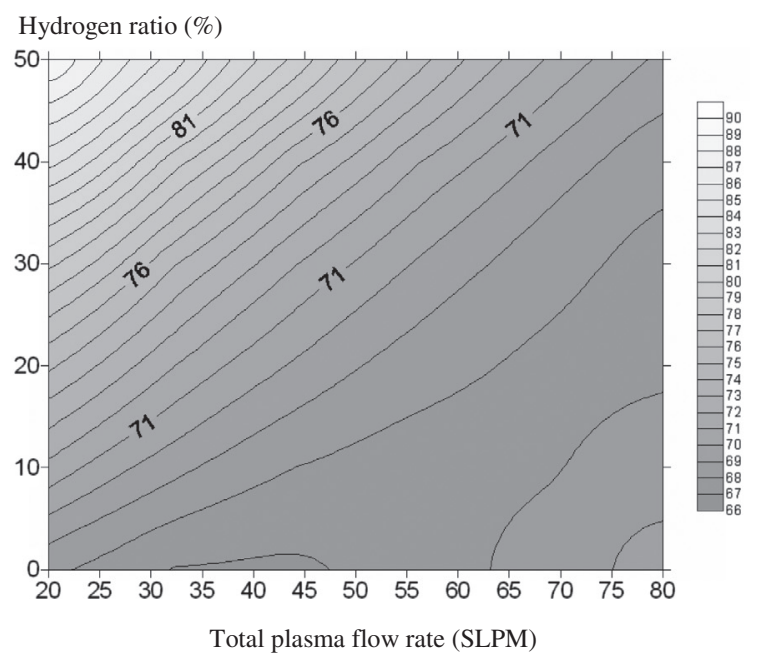

Figure 8. Interaction between the hydrogen ratio and the total plasma flow rate and related effects on (a) titania and (b) alumina phases.

the standard deviation associated to the predicted values shows that in order to obtain the lowest titania ratio, few combinations with the arc current and total plasma few rate are available. These can be identified as a large arc current combined to a small total plasma flow rate.

Figure $7 \mathrm{c}$ shows the effect of the total plasma flow rate on the phase ratios. Alumina ratio is found to decrease and the titania phase to increase as in the case of the individual effect shown in Figure 4.

The last information that can be drawn from the analysis of parameter combinations is related to the coupled effects. These represent the evolution of the phase ratio as function of a couple of parameters as shown in Figure 8. This information allows the prediction of the strength of the parameter interactions. In the case of the hydrogen ratio and total plasma flow rate, this interaction is found to be linear especially in the case of alumina ratio (Figure $8 \mathrm{~b}$ ). The following equations summarize the revealed interactions expressed as planar regressions. 
Couple 1: Hydrogen ratio - total plasma flow rate:

$$
\begin{aligned}
A(\%) & =75-0.15\left(V_{\mathrm{H}_{2}}+V_{\mathrm{Ar}}\right)+0.2\left(V_{\mathrm{H}_{2}} / V_{\mathrm{Ar}}\right)(\%) ; \\
R^{2} & =0.74
\end{aligned}
$$

$$
\begin{aligned}
T(\%) & =16+0.17\left(V_{\mathrm{H}_{2}}+V_{\mathrm{Ar}}\right)-0.45\left(V_{\mathrm{H}_{2}} / V_{\mathrm{Ar}}\right)(\%) ; \\
R^{2} & =0.80
\end{aligned}
$$

Couple 2: arc current - total plasma flow rate:

$$
\begin{aligned}
A(\%) & =83-0.38\left(V_{\mathrm{H}_{2}}+V_{\mathrm{Ar}}\right)+0.03 I(\mathrm{~A}) ; \\
R^{2} & =0.73 \\
T(\%) & =16+0.39\left(V_{\mathrm{H}_{2}}+V_{\mathrm{Ar}}\right)+0.005 \times I(\mathrm{~A}) ; \\
R^{2} & =0.73
\end{aligned}
$$

Couple 3: arc current - hydrogen ratio:

$$
\begin{aligned}
A(\%) & =56+0.48\left(V_{\mathrm{H}_{2}} / V_{\mathrm{Ar}}\right)+0.02 I(\mathrm{~A}) ; \\
R^{2} & =0.80 \\
T(\%) & =41-0.51\left(V_{\mathrm{H}_{2}}+V_{\mathrm{Ar}}\right)-0.018 I(\mathrm{~A}) ; \\
R^{2} & =0.82
\end{aligned}
$$

\section{Conclusions}

Energetic parameters control significantly phase content in alumina-titania coating and especially those parameters affecting in-flight particle temperature.

Titania content was more sensitive to parameter variation than alumina. In average, alumina content varied from $72 \%$ and $89 \%$ whereas titania content varied from $5 \%$ to $13 \%$ in the case where the parameters are varied individually. These corresponded to a relative scatter of $19 \%$ and $61 \%$ for alumina and titania, respectively. In the case where process parameter effects are combined, a larger range is predicted for both phases. When considering the predicted combinations between the variables in the predicted space, the revealed effects are closer in meaning with those obtained by varying each parameter individually and keeping the others to a prescribed level. This allows the generalisation of the predicted effects and the identification of the parameter interactions.

Arc current and hydrogen ratio increased slightly alumina content and decreased significantly titania content. Total plasma gas flow rate had an inverse effect on phase content compared to arc current and hydrogen ratio. The use of nonlinear analysis with ANN and fitting routine showed that correlations between phase content and energetic parameters were weakly non-linear. The relative scatter between experimental and predicted results was satisfying in the case of alumina ( $2 \%$ in average) and significant in the case of titania $(12 \%$ in average).
The interactions between the coupled parameters are to be considered linear as suggested by the planar regressions.

\section{References}

1. Pfender E. 1987. Fundamental studies associated with plasma spray process, in Thermal spray: advances in coatings technology. 14, Houck DL, Editor. ASM International: Materials Park, OH. p. 14-17.

2. Fauchais P, Vardelle M. 1994. Plasma spraying: Present and future. Pure. Appl. Chem., 66, 1247-1258.

3. Moreau C, Gougeon P, Lamontagne M, Lacasse V, Vaudreuil G, Cielo P. 1994. On-line control of the plasma spraying process by monitoring the temperature, velocity and trajectory of in-flight particles, in Thermal spray industrial applications. Berndt $\mathrm{CC}$ et al., Editors. ASM International: Materials Park, OH. p. 431-437.

4. Refke A, Barbezat G, Loch M. 2001. The benefit of an on-line diagnostic system for the optimisation of plasma spray devices and parameters, in Thermal spray 2001: new surfaces for a new millennium, Singapore. Berndt CC et al., Editors. ASM International: Materials Park, OH. p. 765-770.

5. Vaidya A, Bancke G, Sampath S, Herman H. 2001. Influence of process variables on the plasma sprayed coatings: an integrated study, in Thermal spray 2001: new surfaces for a new millennium, Singapore. Berndt CC et al., Editors. ASM International: Materials Park, OH. p. 1345-1349.

6. Döring JE, Vassen R, Stöver D. 2002. The influence of spray parameters on particle properties, in Proc. of International Thermal Spray Conference and Exposition. Lugscheider E et al., Editors. DVS-Verlag GmbH: Düsseldorf. p. 440-445.

7. Lugscheider E, Papenfuß-Janzen N. 2002. Simulation of the influence of spray parameters on particle properties in APS, in Proceedings of International Thermal Spray Conference and Exposition. Lugscheider E et al., Editors. DVS-Verlag GmbH: Düsseldorf. p. 42-46.

8. Prystay M, Gougeon P, Moreau C. 2001. Structure of plasma sprayed zircona coatings tailored by controlling the temperature and velocity of the sprayed particles, J. Therm. Spray Technol., $10,67-75$.

9. Friis M, Persson C, Wigren J. 2001. Influence of particle inflight characteristics on the microstructure of atmospheric plasma sprayed yttria stabilized $\mathrm{ZrO}_{2}$. Surf. Coat. Technol., 141, 115-127.

10. Guessasma S, Montavon G, Coddet C. 2004. Modeling of the APS plasma spray process using artificial neural networks: basis, requirements and an example. Comput. Mater. Sci., 29, 315-333.

11. Bassir D, Guessasma S, Boubakar L. 2009. Hybrid computational strategy based on ANN and GAPS: application for identification of a non-linear model of composite material. Compos. Struct., 88(2), 262-270

12. Guessasma S, Bassir D. 2010. Optimization of the mechanical properties of virtual porous solids using a hybrid approach. Acta Mater., 58, 716-725.

13. Guessasma S, Bassir D. 2010. Identification of mechanical properties of biopolymer composites sensitive to interface effect using hybrid approach. Mech. Mater, 42(3), 344-353.

14. Grihon S, Krog L, Bassir D. 2009. Numerical optimization applied to structure sizing at AIRBUS: a multi-step process. Int. J. Simul. Multi. Design Optim., 3, 432-442. 
15. Guessasma S, Bassir D. 2009. Comparing heuristic and deterministic approaches to optimise mechanical parameters of biopolymer composite materials. Mech. Adv. Mater. Struct, 16, 293-299.

16. Guessasma S, Montavon G, Coddet C. 2003. Neural Networks, design of experiments and other optimizations methodologies to quantify parameter dependence of atmospheric plasma spraying, in Thermal spray 2003: advancing the science and applying the technology. Marple BR et al., Editors. ASM International: Materials Park, OH. p. 939-948.

17. Ananthapadmanabhan PV, Thiyagarajan TK, Sreekumar KP, Satpute RU, Venkatramani N, Ramachandran K. 2003. Co-spraying of alumina-titania: correlation of coating composition and properties with particle behaviour in the plasma jet. Surf. Coat. Technol., 168, 231-240.

18. Gell M, Jordan EH, Sohn YH, Goberman D, Shaw L, Xiao TD. 2001. Development and implementation of plasma sprayed nanostructured ceramic coatings. Surf. Coat. Technol., 146, $48-54$.
19. Nylén P, Wigren J, Idetjärn J, Pejryd L. 2001. On-line Microstructure and property control of thermal sprayed abrasive coatings, in Thermal spray 2001: new surfaces for a new millennium Singapore. Berndt $\mathrm{CC}$ et al., Editors. ASM International: Materials Park, OH. p. 1213-1220.

20. Galvão Novaes C, Almeida Bezerra M, Galvão Paranhos da Silva E, Pinto dos Santos AM, da Silva Romão IL, Santos Neto JH. 2016. A review of multivariate designs applied to the optimization of methods based on inductively coupled plasma optical emission spectrometry (ICP OES). Microchem. J., 128, 331-346.

21. Lin CM, Yen SH, Su CY. 2016. Measurement and optimization of atmospheric plasma sprayed CoMoCrSi coatings parameters on Ti-6Al-4 V substrates affecting microstructural and properties using hybrid abductor induction mechanism. Measurement, 94, 157-167.

Cite this article as: Guessasma S \& Bassir D: Neural network computation for the evaluation of process rendering: application to thermally sprayed coatings. Int. J. Simul. Multisci. Des. Optim., 2017, 8, A10. 